\title{
THE PREVENTION OF DEFORMITY IN THE SEVERELY PARALYSED HAND
}

\author{
By D. J. E. Cheshire, M.B., B.S., D.Phys.Med. and \\ GlenYs Rowe, Dip.Occ.Ther.* \\ Spinal Injuries Centre, Austin Hospital, Heidelberg, Victoria, Australia
}

THE human hand represents the highest attainment in bio-mechanical sophistication, but it is much more than an organ of grasp and manipulation; it is also an organ of self-expression, an extension of speech and of personality. Furthermore, the hand is usually exposed to the sight of every casual observer. When creating a rehabilitation programme for a patient with a severely paralysed hand, it is fundamental that due emphasis shall be given both to the physical and to the psychological components of rehabilitation. There is no more important feature in this programme than to prevent a hand deformity which may both impair physical efficiency and be a potent factor in the development of psycho-social maladjustment, especially if the paralysis of the hand is only one part of a major compound disability, such as tetraplegia.

These hand deformities, characteristically the claw hand, the flipper hand and the intrinsic minus hand, can be prevented, but the techniques in general use have been found to be inadequate.

Mechanism of Deformity. Both the frequency and the importance of the potential deformities of the paralysed hand demand that all possible steps be taken to prevent them, but this prevention itself depends on understanding the mechanisms which may produce modifications in the length or the elasticity of soft tissues. The causes of deformity in the paralysed limb are poorly understood. Writings between I9I I and I954 variously attributed deformity in poliomyelitis to oedema in a paralysed limb, shortening of active unopposed muscles, fibrosis in paralysed muscles, adhesions between muscles and their sheaths, stretching of paralysed muscles, failure to stretch paralysed muscles, injudicious splintage, failure to splint, muscle imbalance, posture, gravity and collagen deposition of unknown cause (Jones, I9II; Lovett, I922; Ghormley \& Allen, I949; Bennett, I952; Seddon, I954).

Study of approximately 250 patients with cervical spinal paralysis has led to the conclusion that, other things being equal, the tetraplegic who is most liable to develop hand deformity is the patient who develops oedema of the hand, or is a middle-aged manual worker with fibrotic hands, and most difficult of all, has fibrotic hands and develops oedema.

This opinion was strengthened by a recent paper in which Sharrard (1967) described the mechanisms of paralytic deformity. In summary, he stated that there are three mechanisms which can produce modifications in the length or elasticity of soft tissues. These are:

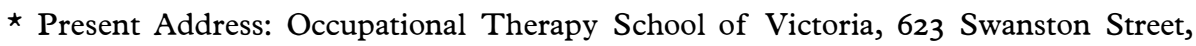
Melbourne. 
I. Acute Neurological Contracture. In acute paralytic conditions, loss of elasticity and shortening may develop in tendons, fasciae, intermuscular septa, joint capsules and ligaments in which collagen is deposited. If length can be maintained by stretching the soft tissues during the acute phase, deformity can be prevented; otherwise the deposited collagen becomes converted into strong fibrous tissue and a fixed deformity results.

The factors responsible for the rapid deposition of collagen in acute neurological contracture are not known.

2. Postural Contracture. If a paralysed limb is kept immobilised, or if full passive movements are not performed, deformity may develop. If there be also oedema, collagen is deposited in the oedema fluid and leads to contractures and adhesions.

The daily maintenance of a full range of passive movements, and the effective use of measures to prevent oedema will be sufficient to prevent the development of deformity.

3. Deformity from Muscle Imbalance. This deformity differs in several ways from those already described. It does not occur in any limb with normal muscles; it does not develop in a flail limb; and it is seen much more often in children than in adults. In the context of the tetraplegic hand, this type of deformity is perhaps best shown in the intrinsic minus hand. Treatment is essentially a long-term problem and corrective splints may be required indefinitely.

In both acute neurological contractures and postural contractures, the contracture is caused by the conversion of deposited collagen into fibrous tissue. This collagen is deposited in oedema fluid. Hence, to prevent oedema is an essential step in the prevention of deformity in the severely paralysed hand.

To prevent deformity in the paralysed hand, three criteria must be rigidly observed:

I. A full range of passive movement must be preserved in all joints.

2. In between physiotherapy treatments the hand must be supported in a position which maintains the length of the soft tissues, particularly the collateral ligaments of the metacarpo-phalangeal and interphalangeal joints, and the muscles of the adductor web.

3. A technique must be developed which will minimise the development of oedema in the paralysed hand.

The 'Boxing Glove' Splint. In I965, as these ideas concerning the importance of oedema in the genesis of hand deformities were developing, one of us (D. J. E. Cheshire) attended a lecture by Professor J. I. P. James on the subject of Hand Injuries. In this lecture, James laid great emphasis on the importance of immobilising the injured hand in a position of maximum soft tissue length and of minimising oedema. He described a technique of compression bandaging which he called the 'Boxing Glove' bandage.

A few weeks later, a I7-year-old boy was admitted to the Centre two hours after having fallen from a moving train, sustaining a vertical compression fracture of the fifth cervical vertebra with tetraplegia and multiple injuries which included fractures of the second, third, fourth and fifth metacarpals of the right hand. The left upper limb was uninjured. With James' lecture in mind, the right hand was treated by maintaining the re-aligned metacarpals over a palmar pad of cottonwool with the metacarpo-phalangeal joints flexed to $90^{\circ}$ and with about $20^{\circ}$ of 
flexion at the interphalangeal joints. A 'boxing glove' compression bandage was then applied to minimise oedema. Despite inability to perform passive movements of the hand during the time of metacarpal immobilisation, it was observed, at the end of six weeks, that there was less oedema and thickening of the right, and injured hand than there was of the uninjured left hand, which had been treated by the then routine technique of maintenance of the anatomical 'position of function' on a palm roll and twice daily passive movements of all joints. It was also observed that the patient rapidly regained a full range of movement at the metacarpophalangeal joints of the right hand, but had developed some extension contracture at these joints on the left side and the restoration of the full range was significantly delayed.

This case illustrates two fundamental points upon which our ideas are based:

I. Palm rolls, as usually used, place the metacarpo-phalangeal joints in $45^{\circ}$ of flexion, or less (fig. I). It is granted that this is the 'position of function', but it is also a position in which severe functional contracture can develop at the metacarpo-phalangeal joints. The study of the anatomy of the metacarpo-phalangeal and interphalangeal joints, as recently published by Kuczynski (I968), is the basis upon which James (I968) teaches that, because the collateral ligaments of the metacarpo-phalangeal joints are at their maximum tension at $90^{\circ}$ flexion, it is only by immobilising the hand in that position that one may ensure that the chances of contracture in these ligaments are minimised (fig. 2).

2. Previous techniques did not prevent oedema of the paralysed hand, and the significance of oedema, in terms of future contractures, is such that a method for its prevention had to be developed.

Such is the derivation of the use of the 'boxing glove' splint in the prevention of deformity in the severely paralysed hand.

Method of Application of 'Boxing Glove' Splint. I. Hand Position. The wrist is placed at $45^{\circ}$ of dorsi-flexion, the second to fifth metacarpo-phalangeal joints are placed at an angle as near to $90^{\circ}$ as possible, and the interphalangeal joints are placed at $20-30^{\circ}$ of flexion. The thumb is placed in a partially opposed position with the adductor web on full stretch and the pad of the thumb vertically beneath the pads of the second and third fingers. One is thus already starting to think about the position for a thumb-finger tenodesis grip.

2. The Palmar Pad. As the 'boxing glove' technique evolved it became apparent that the usual palm roll was too large in diameter to permit flexion of the metacarpo-phalangeal joints beyond $45^{\circ}$. In order to immobilise the hand in the optimum position which is described above, it is necessary to abandon the concept of a palm roll and to make a palm pad for each individual hand. For accurate shaping, cheapness and availability of material, and, not least, because of the absence of sensation in the hand, a simple cotton-wool pad is preferred. Time and experiment is needed to ensure that the pad is of the correct size and shape (figs. $3 \mathrm{~A}$ and $\mathrm{B})$.

3. A Wrist Cock-up Splint. When considering the problem of preventing deformity in the severely paralysed hand it is also necessary to prevent a flexion contracture at the wrist, and to prevent interference with the re-education of a weak extensor carpi-radialis through the over-stretching of this muscle in the early post-accident phase. In many patients it is therefore wise to incorporate a light 


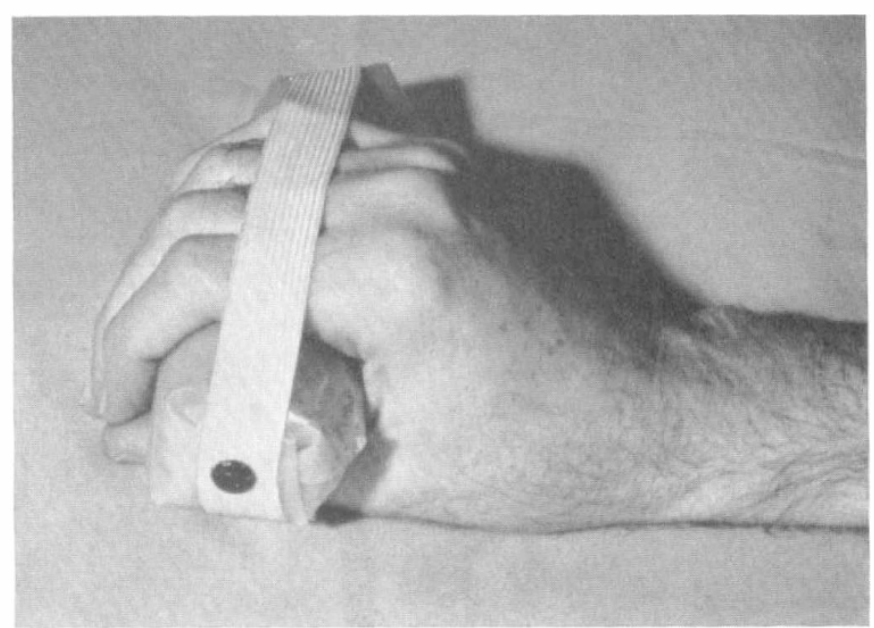

FIG. I

The type of palm roll in common use. There is approximately $35^{\circ}$ flexion at the metacarpo-phalangeal joints.
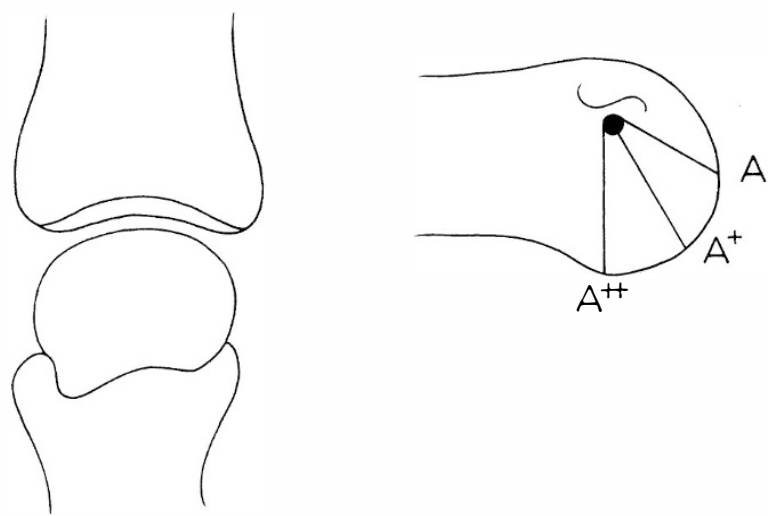

FIG. 2

The metacarpo-phalangeal joint. $\mathrm{A} \rightarrow \mathrm{A}+\rightarrow \mathrm{A}++$ demonstrate the sagittal cam effect of the metacarpal head and the increasing stretch of the collateral ligaments as metacarpophalangeal flexion increases to $90^{\circ}$. (Modified from Kuczynski, I968).

wrist cock-up splint into the boxing glove splint. A combined wrist cock-up splint and palmar bar can be made in an appropriate plastic material by the occupational therapist who is treating the patient (figs. $4 \mathrm{~A}, \mathrm{~B}, \mathrm{C}$ ).

4. Prevention of Pressure. In any technique of compression bandaging, and particularly when the part being bandaged is anaesthetic, it is essential to take all possible steps to avoid the patient's developing the effects of pressure. A thick layer of cotton-wool laid over the dorsum of the hand and forearm not only prevents this pressure, but also ensures even and effective compression (fig. 5). 


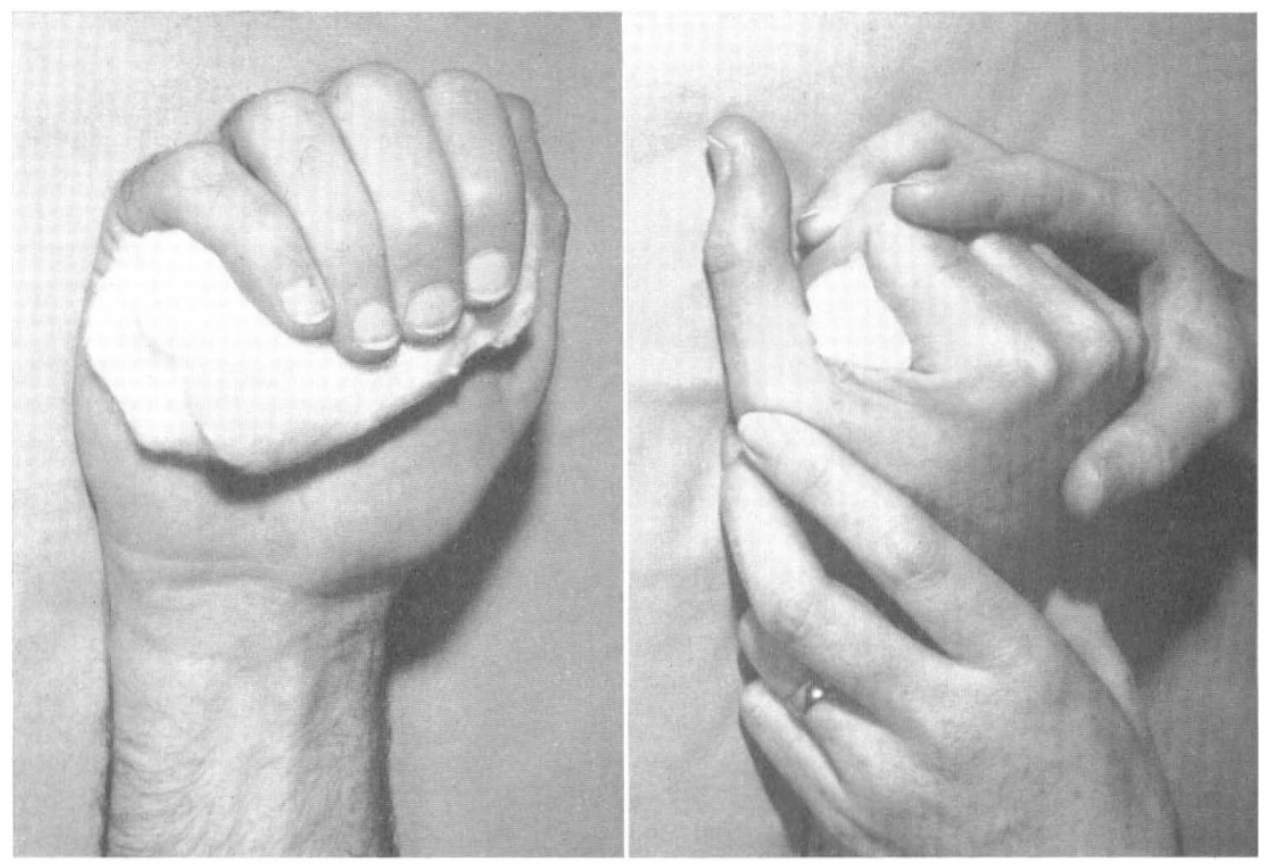

FIG. 3

A, The palmar pad of cotton-wool. B, positioning of the hand prior to bandaging. There is approximately $90^{\circ}$ flexion at the second metacarpo-phalangeal joint.
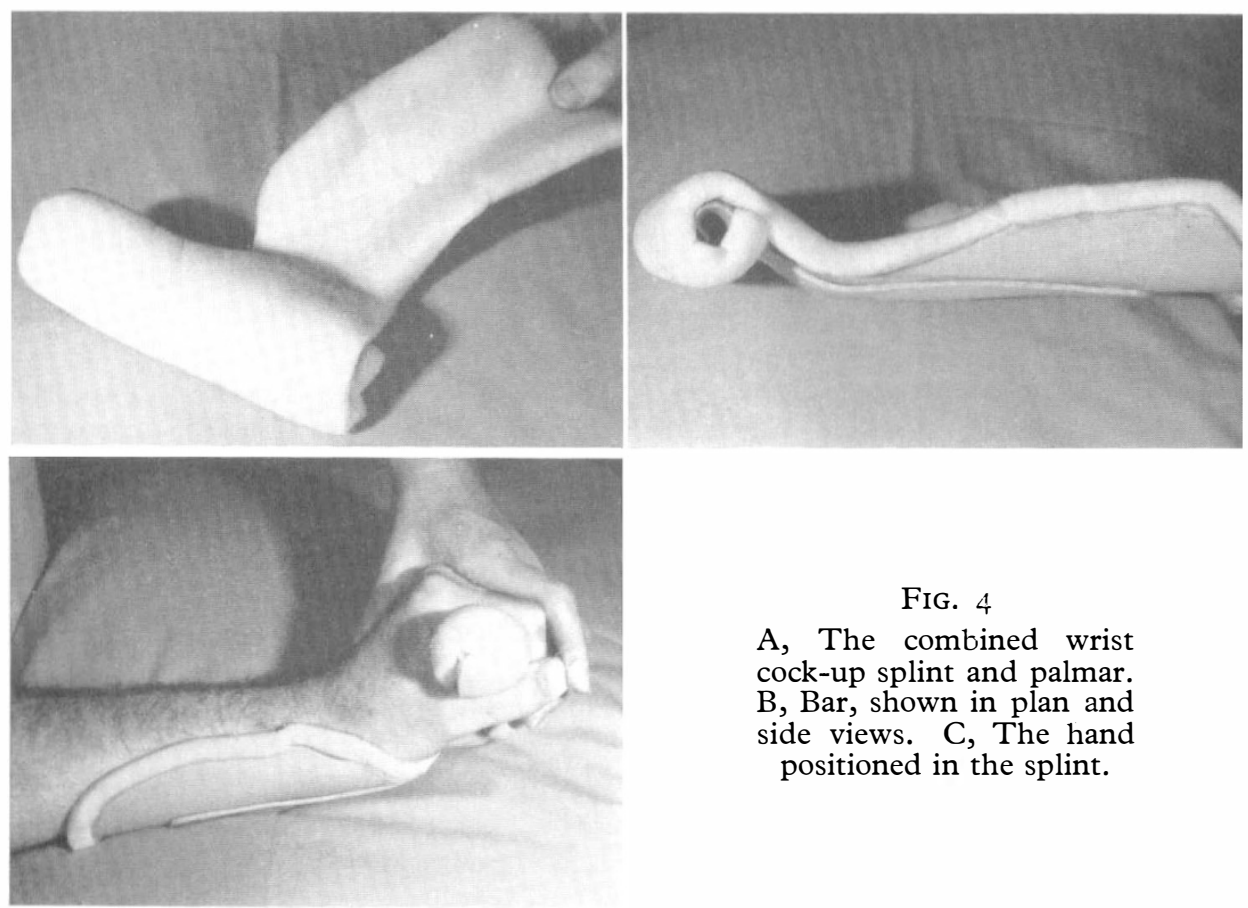

FIG. 4

A, The combined wrist cock-up splint and palmar. $\mathrm{B}$, Bar, shown in plan and side views. C, The hand positioned in the splint. 


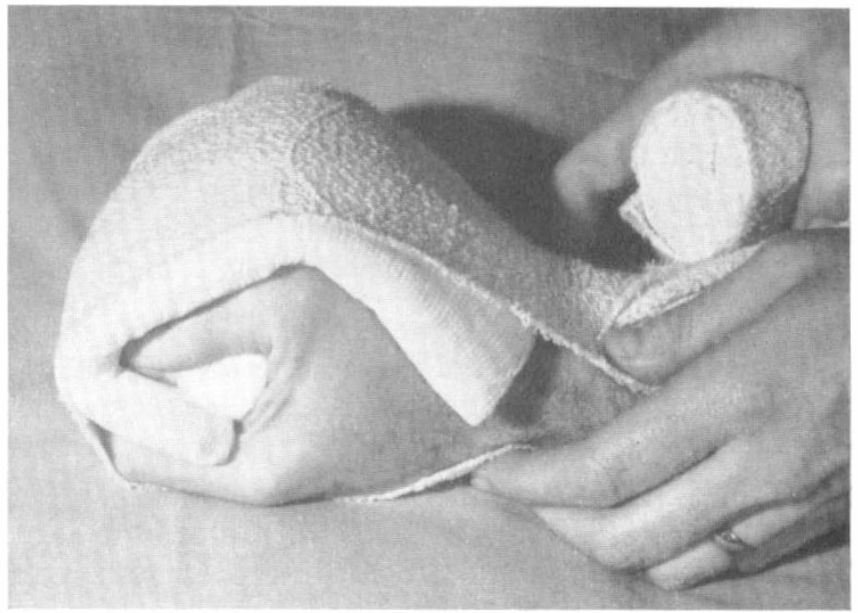

FIG. 5

The commencement of the pressure bandage over a thick layer of cotton-wool.

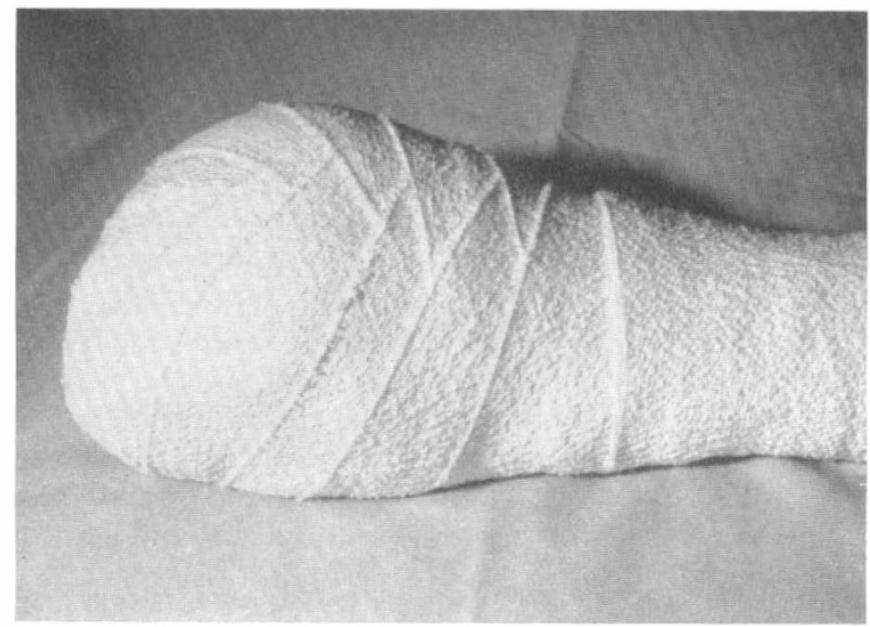

FIG. 6

The completed 'boxing glove' splint.

5. The Application of the Compression Bandage. The compression bandage is completed with two 3 -inch $(7 \cdot 6-\mathrm{cm}$.) crepe bandages. The bandage is applied in the traditional manner of a stump bandage (fig. 6 ).

Of particular importance in the prevention of oedema of the dorsum of the hand are those sections of the bandage which pass longitudinally along the forearm and over the dorsum of the hand.

6. Elevation. Further to minimise the development of postural oedema, it is wise, when possible, to elevate the hand relative to the shoulder, by placing the arm upon a pillow. 
The 'boxing glove' splints are removed twice daily in order that the physiotherapist may put all joints through a full range of movement, and in order that the hand may be inspected to ensure that there are no pressure effects; they are also removed for occupational therapy, otherwise the splints are worn day and night during the acute phase until there is no longer any tendency to oedema. This period of splintage usually coincides with the patient's confinement to bedroughly two to three months. In some patients, especially those with fibrotic hands, it may be necessary to continue splintage, at least at night, for many months.

\section{DISCUSSION}

In the past, the early management of the tetraplegic hand has been poor, avoidable deformities have been permitted, and these have had profound effects both in limiting physical potential and in the development of psychological disturbances. Erdman and Bendler (I96I) dismiss the problems of early management in saying 'the hands are placed in the position of function with attention to maintaining the opposing position of the thumb' and 'passive motion to all paralysed extremities should be carried out daily to maintain motion of the joints and prevent contractures'. Lamb (I963) is barely more specific, and Friedland (I968) in a 75-page chapter on 'Rehabilitation in Spinal Cord Injuries' does not mention hand deformities in the tetraplegic, far less their prevention. A review of the British and American rehabilitation literature for the past five years, discloses only one short article which is remotely relevant. This article (Goldberg \& Moore, 1965) describes a palm roll which is quite a useful improvement on other types, but still does not permit metacarpo-phalangeal flexion beyond about $45^{\circ}$. There can be few who have not studied the work of Nickel and his team at Rancho Los Amigos Hospital, and are not following at least some of his teachings. Yet the teaching from Rancho is that deformity is preventable by the use of a basic positioning splint - the long or short opponens splint-and the performance of regular passive movements. In the excellent papers of Nickel et al. (I963) and Yerxa (I966) there is no mention of the possibility of oedema of the hand, and the present authors have two objections to reliance on a basic positioning splint in the early weeks, even in those Centres where such splints are readily available. Our first objection is that when Nickel et al. (1963) state that with such a splint 'the fingers are free to fall into a relaxed semi-flexed position' the fingers do not fall beyond about $45^{\circ}$ of flexion at the metacarpo-phalangeal joints, and secondly, the straps of the splint which secure the splint to the forearm can be a factor in causing oedema of the hand. It is probably not surprising that this has been a neglected subject, and its neglect is doubtless associated with delayed admission of the tetraplegic to a specialised Centre. By the time many tetraplegics are admitted to Spinal Injuries Rehabilitation Centres, the stage of oedema is passed, and hand deformities have become established.

The 'boxing glove' splint is being used routinely in the treatment of the hands of acute tetraplegics to minimise the development of acute oedema, to prevent early shortening of the collateral ligaments of the metacarpo-phalangeal joints, and to maintain the thumb in adduction and opposition for palmar pad prehension with the second and third fingers.

The severe and often grotesque deformities which can occur in the tetraplegic hand may cause both increasing physical inefficiency and psychological distur- 
bance. They begin at the onset of the condition. It is therefore imperative that prevention of hand deformities shall start immediately the patient comes under treatment. These preventative measures must be maintained constantly as the deforming agents are present both day and night. Whilst oedema may decrease after the acute phase of the paralysis, spasticity will often increase, and muscle imbalance and postural deformities remain constant. It was not until the 'boxing glove' splint was used that oedema was successfully prevented. Prior to this, it was constantly observed that tetraplegic hands lost their natural flexibility after about eight weeks in spite of good-quality physiotherapy with full passive motion to all joints twice daily. By this time non-functional contractures were well established, and continued despite an intensive rehabilitation programme. Moreover, these contractures rendered unrealistic all long-term attempts to achieve a three-point tenodesis prehension.

To enable the tetraplegic to achieve his full functional potential and also to ensure an acceptable cosmetic result, it is necessary to prevent contractures and deformity occurring in the first two months.

To prevent these contractures requires the maintenance of full length in the relevant soft tissues, and the prevention of oedema. If the 'boxing glove' splint is used in the early stages and the patient thereafter uses a resting splint which is appropriate to his residual anatomical status, he is in the best possible functional condition for his practical rehabilitation and for his education towards maximum independence.

\section{SUMMARY}

The first task in the rehabilitation of the severely paralysed hand is to prevent deformity, but prevention itself dependent upon an understanding of the mechanisms which produce modifications in the length or elasticity of soft tissues. These are acute neurological contracture, postural contracture, and deformity from muscle imbalance and/or spasticity.

In the tetraplegic the effects of posture and oedema are of such importance that the 'boxing glove' splint has been developed, and is routinely used to minimise oedema and prevent deformity.

The 'boxing glove' splint is described in detail.

\section{RÉSUMÉ}

Le premier devoir de la rééducation de la main paralysée, est de prévenir les difformités. Mais, la prévention elle-même dépend de la compréhension des mécanismes qui produisent les modifications dans la longueur et l'élasticité des tissus.

Ceux-ci sont: les contractures neurologiques, posturales et les difformités par un manque d'équilibre musculaire et/ou la spasticité.

Chez le tétraplégique, les effets de posture et d'oedème sont de telle importance que l'attelle dite du 'gant de boxe' a été développée et est utilisée de façon à diminuer l'oedème et prévenir les difformités.

L'attelle 'gant de boxe' est décrite en détail.

\section{ZUSAMMENFASSUNG}

Die erste Aufgabe in der Rehabilitation der schwer gelähmten Hand ist die Verhütung von Deformierung, aber die Verhütung selber hängt von dem Verständnis der Mechanismen $\mathrm{ab}$, die eine Modifizierung der Länge oder Elastizität der weichen Gewebe hervorruft. 
Diese sind akute neurologische Kontrakturen, Lage bedingte Kontrakturen und Deformitäten als Folge von Balancestörungen von Muskeln und/oder der Spastizität.

In der Tetraplegie ist der Effekt von Lage und Oedem von solcher Bedeutung, dass die 'Boxer-Handschuh' Schiene entwickelt wurde und als Routinemassnahme angewandt wird, um Oedem zu verringern und Deformität zu verhüten.

Die 'Boxer-Handschuh' Schiene wird in Einzelheiten beschrieben.

The 'boxing glove' technique was originally devised by Professor J. I. P. James. We wish both to acknowledge this fact and to thank Professor James for his help and encouragement in the preparation of this paper.

We also acknowledge our gratitude to the Winston Churchill Memorial Trust, as it was the award of a Travelling Fellowship to one of us (G. R.) which stimulated a deeper study of the rehabilitation problems of the tetraplegic hand.

Many occupational therapists, physiotherapists and nurses have worked on this project, but we would particularly mention Miss Jean Beveridge, who conceived the splint illustrated in Figure 4.

\section{REFERENCES}

Bennetr, R. L. (1952). Proceedings of Second international Poliomyelitis Conference, p. 26I. Philadelphia: Lippincott.

Erdman, W. J. \& Bendler, E. M. (I96I). In The Spinal Cord, ed. Austin, G. p. 434. Springfield: Thomas.

FrIEDland, F. (1968). In Rehabilitation in Medicine, pp. 460-535, ed. Licht, S. New Haven: Licht.

GHORMLEY, R. K. \& Allen, C. S. (1949). Proceedings of First International Poliomyelitis Conference, p. I48. Philadelphia: Lippincott.

Goldberg, M. J. \& Moore, C. R. (1965). Archives of Physical Medicine, 46, 48I.

JAMES, J. I. P. (I968). Personal Communication.

JONES, R. (I9II). British Medical fournal, 2, 1520.

KuCZYNSKI, K. (1968). Fournal of Bone and Foint Surgery, 50-B, 656.

Lamb, D. W. (1963). In Proceedings of a Symposium on Spinal Injuries, p. I2 I., ed. Harris, P., Royal College of Surgeons of Edinburgh

Lovett, R. W. (1922). Fournal of the American Medical Association, 78, 1607.

Nickel, V. L., Perry, J. \& Garrett, A. L. (1963). Fournal of Bone and foint Surgery, 45-A, 933.

Seddon, H. J. (1954). In British Surgical Practice, Surgical Progress, p. I62. London: Butterworth.

SHARRARD, W. J. W. (1967). Fournal of Bone and foint Surgery, 49-B. 73I.

YerXa, E. J. (I966). Proceedings of Fourth International Congress of the World Federation of Occupational Therapists, p. I57. London: Exerpta Medica. 